Article

\title{
Soil Bacterial and Fungal Community Responses to Throughfall Reduction in a Eucalyptus Plantation in Southern China
}

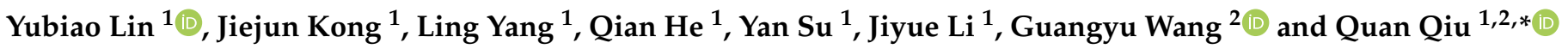 \\ 1 Guangdong Key Laboratory for Innovative Development and Utilization of Forest Plant Germplasm, \\ College of Forestry and Landscape Architecture, South China Agricultural University, \\ Guangzhou 510642, China; yubiaolin@stu.scau.edu.cn (Y.L.); 20193154014@stu.scau.edu.cn (J.K.); \\ yangling@stu.scau.edu.cn (L.Y.); heqian@scau.edu.cn (Q.H.); suyan@scau.edu.cn (Y.S.); \\ ljyue@scau.edu.cn (J.L.) \\ 2 Faculty of Forestry, University of British Columbia, Vancouver, BC V6T 1Z4, Canada; guangyu.wang@ubc.ca \\ * Correspondence: qqiu@scau.edu.cn
}

check for updates

Citation: Lin, Y.; Kong, J.; Yang, L.; He, Q.; Su, Y.; Li, J.; Wang, G.; Qiu, Q. Soil Bacterial and Fungal Community Responses to Throughfall Reduction in a Eucalyptus Plantation in Southern China. Forests 2022, 13, 37. https:// doi.org/10.3390/f13010037

Academic Editor: Bartosz Adamczyk

Received: 20 November 2021

Accepted: 27 December 2021

Published: 31 December 2021

Publisher's Note: MDPI stays neutral with regard to jurisdictional claims in published maps and institutional affiliations.

Copyright: (C) 2021 by the authors. Licensee MDPI, Basel, Switzerland. This article is an open access article distributed under the terms and conditions of the Creative Commons Attribution (CC BY) license (https:// creativecommons.org/licenses/by/ $4.0 /)$.

\begin{abstract}
In subtropical plantations in southern China, how soil microbial communities respond to climate change-induced drought is poorly understood. A field experiment was conducted in a subtropical Eucalyptus plantation to determine the impacts of $50 \%$ of throughfall reduction (TR) on soil microbial community composition, function, and soil physicochemical properties. Results showed that TR reduced soil water content (SWC) and soil available phosphorus (AP) content. TR significantly altered 196 bacterial operational taxonomic units (OTUs), most of them belonging to Acidobacteria, Actinobacteria, and Proteobacteria, while there were fewer changes in fungal OTUs. At the phylum level, TR increased the relative abundance of Acidobacteria at 0-20 cm soil depth by $37.18 \%$, but failed to influence the relative abundance of the fungal phylum. Notably, TR did not alter the alpha diversity of the bacterial and fungal communities. The redundancy analysis showed that the bacterial communities were significantly correlated with SWC, and fungal communities were significantly correlated with AP content. According to predictions of bacterial and fungal community functions using PICRUSt2 and FUNGuild platforms, TR had different effects on both bacterial and fungal communities. Overall, SWC and AP decreased during TR, resulting in greater changes in soil bacterial community structure, but did not dramatically change soil fungal community structure.
\end{abstract}

Keywords: throughfall reduction; high-throughput sequencing; abundance; functional diversity; soil microbial community

\section{Introduction}

Changes in precipitation will affect the biogeochemical cycle of terrestrial ecosystems as a result of global climate change [1]. It has been reported that future predictions of precipitation patterns on a regional scale are uncertain. Global precipitation patterns, including the amount, intensity, and timing of rainfall, have been changing in almost all regions of the world over the last few decades [2]. The climate change model PRECIS simulation results show that the winter precipitation in southern China will decrease significantly in the future, resulting in summer floods and winter droughts [3]. These changes will change the $\mathrm{C}$ and $\mathrm{N}$ cycling of terrestrial ecosystem and the net primary productivity of vegetation [4]. Drought caused by precipitation reduction will have important ecological consequences on ecosystems, especially forest ecosystems. Soil microorganisms have a significant feedback effect on the huge carbon pool of subtropical forest, but the current research lacks an understanding of the sensitivity of microbial communities to precipitation reduction.

Precipitation reduction has a direct effect on soil water content, while water availability affects the activity and growth of both plants and soil microorganisms [5], as well as the biogeochemical processes associated with them [6,7]. Soil microorganisms play an important role in soil nutrient transformation and can decompose recalcitrant matter, such as cellulose 
and lignin [8,9]. Multiple studies have demonstrated that soil water availability, which is directly influenced by precipitation input, affects soil microbial community composition and function [10-12], but the direction and magnitude of soil microbial community responses to precipitation changes remain uncertain $[13,14]$. Generally, fungi are thought to be more tolerant to drought than bacteria because they are able to create large hyphal networks that facilitate water transfer over long distances, allowing them to explore water-filled soil pores not accessible to plant roots [15]. The reduction of precipitation leads to soil water shortage, inhibits the diffusion of nutrients, changes the potential energy of soil solution, and leads to the dehydration, and even death, of microbial cells $[13,14]$. It will also change plant composition and litter decomposition rates [16], indirectly affecting the nutrient availability of soil microorganisms.

At present, there are two main ways to study the relationship between precipitation and soil microbial community. One is to study the distribution law of microorganisms affected by the change of natural precipitation [17], and the other is to conduct water control experiments, such as dry-wet cycles in laboratory or field precipitation control [18,19]. The field control experiments can provide convincing evidence for the impact of increasing frequency, duration, and intensity of drought on soil microorganisms in the future. This helps to predict the response of soil microorganisms to future environmental changes and formulate effective and sustainable management strategies for forest ecosystems under drought conditions.

Eucalyptus, one of the three major artificial forest species in the world, has been planted on more than 5.46 million hectares in China, accounting for 2.5 percent of China's total forest area and producing more than one-third of the country's total wood production [20]. It is of great significance to study the response of Eucalyptus plantation ecosystem to climate change. However, the effects of drought stress caused by the change of precipitation reduction on soil microbial community composition and function of Eucalyptus plantation have not been reported yet. In order to fill this gap, we investigated the response of soil microbial community composition and function to simulated throughfall reduction in a Eucalyptus plantation in southern subtropical China by establishing a fixed sample plot with throughfall reduction. Specifically, we aimed to address the following questions: (i) Do changes in the throughfall reduction alter microbial community composition and function in the Eucalyptus plantation? (ii) How does the response vary of microbial groups to the throughfall reduction? We hypothesized that fungi would be more resistant to throughfall reduction than bacterial. (iii) What are the other soil factors that are altered by the throughfall reduction, and how would they be related to the responses of microbial community composition? We hypothesized that the change of soil C, N, and P availability caused by the throughfall reduction may indirectly shape the microbial community composition.

\section{Materials and Methods}

\subsection{Study Site}

The study was conducted at SCAU Teaching and Research Base in Zengcheng District, Guangzhou $\left(23^{\circ} 14^{\prime} 48 \mathrm{~N}, 113^{\circ} 38^{\prime} 20 \mathrm{E}\right)$. This area experiences a south subtropical monsoon climate, with a wet season from April to September and a dry season from October to March. The mean annual air temperature is $21.9{ }^{\circ} \mathrm{C}$, and the mean annual precipitation is $2004.5 \mathrm{~mm}$, about $80 \%$ of which occurs during the rainy season (April to September). During the dry season of 2019-2021, Guangzhou's meteorological data shows monthly precipitation ranged from 0.0 to $137.7 \mathrm{~mm}$ and averaged $33.7 \mathrm{~mm}$ in Zengcheng district (Figure 1). 


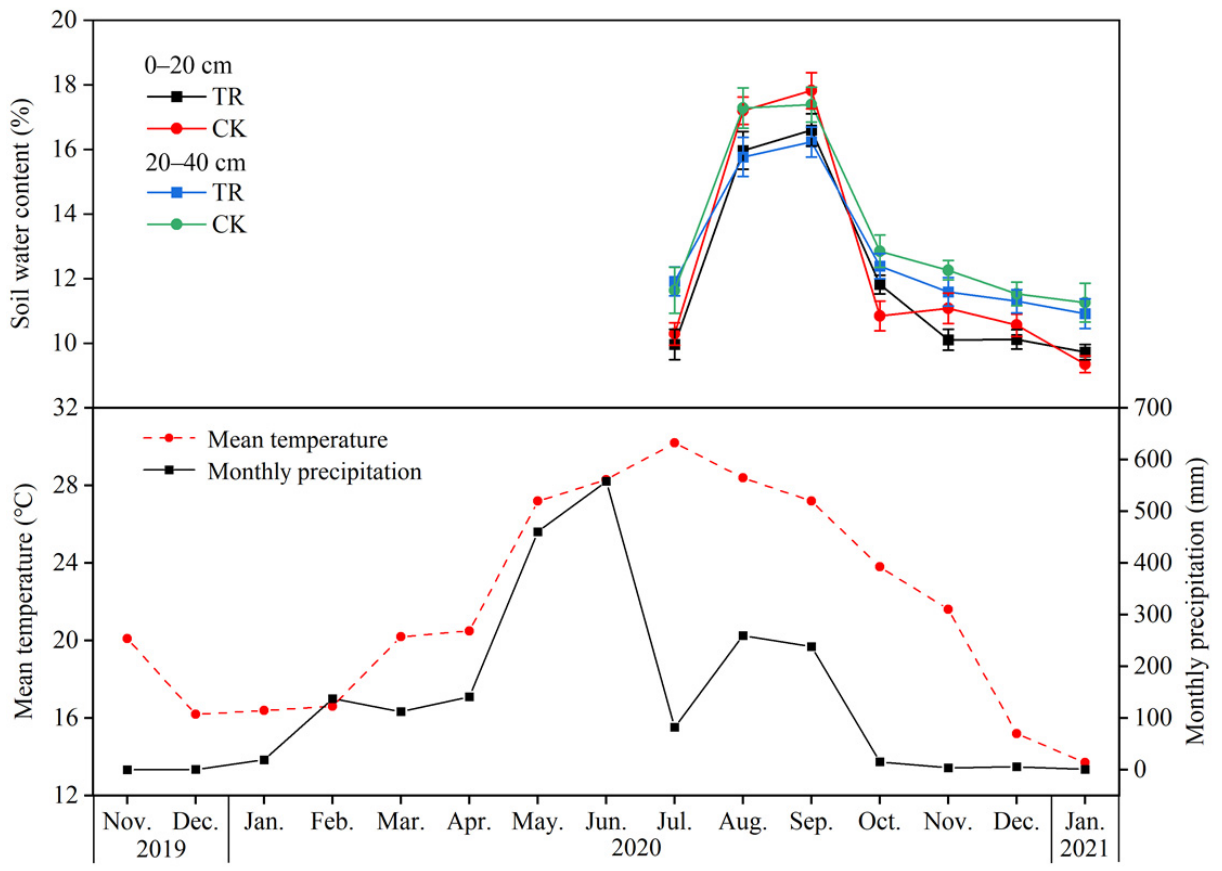

Figure 1. Soil water content, monthly precipitation and mean temperature from November 2020 to January 2021 after setting penetrating rain interception device. CK, control; TR, throughfall reduction, the same below.

\subsection{Experimental Design and Soil Sampling}

In November 2019, six experimental plots in size of $10 \times 10 \mathrm{~m}$ were established within the study area. Three plots were assigned for the throughfall reduction treatment (hereafter TR treatment), and three paired plots were designed as controls. In each TR plot, a set of steel frames was set up on standing steel pillars to support the transparent throughfall reduction shelters. Each exclusion shelter was V-shaped and was fixed on stainless steel beams. The exclusion shelters were pitched consistent with the slope of the plots and connected to PVC troughs located at the lower slope so that the excluded throughfall could be drained out of the plots. Depending on the distribution of trees in the plots, the width of each shelter ranged from 0.7 to $1 \mathrm{~m}$-covering $50 \%$ of the total plot area-were used in each TR plot to exclude throughfall (Figure S1). Due to the lack of quantitative projections on the reduction of future rainfall in the region, we used a similar throughfall reduction rate (i.e., $50 \%$ ) as those had been used in throughfall reduction experiments of subtropical plantations [21]. The control plots were set up without throughfall reduction, but we trenched the four sides of each TR plot to $60-80 \mathrm{~cm}$ depth using $1 \mathrm{~m}$ height PVC boards to prevent the lateral water flow. The experiment lasted from November 2019 to January 2021.

\subsection{Soil Sampling and Soil Properties Analyses}

On 26 January 2021, five sampling points were selected randomly within each plot, and $0-20 \mathrm{~cm}$ and $20-40 \mathrm{~cm}$ soil samples were collected. After the removal of litter, stones, and other dead soil animals, soil samples were sieved through a $2 \mathrm{~mm}$ mesh immediately in the field and the five soil cores in the same plot were homogenized into a composite sample. Each composite sample was further divided into two subsamples and stored for analyzing soil chemical properties (air-dried and stored at $4{ }^{\circ} \mathrm{C}$ ) and amplicon sequencing (stored at $-80^{\circ} \mathrm{C}$ ), respectively. A total of 12 samples were sampled (2 precipitation treatments $\times$ 2 soil depths $\times 3$ replicate plots).

Soil water content (SWC) was measured by oven drying $10 \mathrm{~g}$ of fresh soil sample at $105^{\circ} \mathrm{C}$ for $24 \mathrm{~h}$. Total organic carbon (TOC) was determined by the $\mathrm{K}_{2} \mathrm{Cr}_{2} \mathrm{O}_{7}$ titration 
method. Total nitrogen (TN) was measured by the indophenol blue colorimetric method and total phosphorus (TP) by the molybdenum antimony blue colorimetric method [22]. Soil organic matter (SOM) was determined by potassium dichromate oxidation external heating method. Alkali-hydrolyzed nitrogen (AHN) was determined by alkali hydrolysis diffusion method. Available phosphorus (AP) was determined by spectrophotometry.

\subsection{DNA Extraction, PCR Amplification, and Illumina Sequencing}

Soil microbial DNA was extracted from Eucalyptus soil samples using the E.Z.N.A. ${ }^{\circledR}$ soil DNA Kit (Omega Bio-tek, Norcross, GA, USA). The bacterial 16S rRNA genes were amplified using primer sets 338F/806R [23]. For fungi, the primers used for the amplification of the partial ITS region were ITS1F/ITS2R [24]. The PCR conditions for the 16S rRNA gene were as follows: an initial denaturation at $95^{\circ} \mathrm{C}$ for $3 \mathrm{~min}$; followed by 27 cycles of $95{ }^{\circ} \mathrm{C}$ for $30 \mathrm{~s}, 30 \mathrm{~s}$ at $55^{\circ} \mathrm{C}, 68^{\circ} \mathrm{C}$ for $45 \mathrm{~s}$, and a final extraction at $72{ }^{\circ} \mathrm{C}$ for $10 \mathrm{~min}$. The PCR conditions for the ITS1 region were as follows: initial denaturation at $95^{\circ} \mathrm{C}$ for $3 \mathrm{~min}$; 35 cycles of $30 \mathrm{~s}$ at $95^{\circ} \mathrm{C}, 30 \mathrm{~s}$ at $55^{\circ} \mathrm{C}$, and $45 \mathrm{~s}$ at $72{ }^{\circ} \mathrm{C}$; and a final extraction at $72{ }^{\circ} \mathrm{C}$ for $5 \mathrm{~min}$. The $16 \mathrm{~S}$ rDNA and ITS2 gene fragments were sequenced using the Illumina MiSeq PE300 platform (Illumina, USA). Raw amplicon sequences were deposited in the Sequence Read Archive (SRA) and assigned the following BioProject accession number: PRJNA774083 and PRJNA774151.

Paired end reads were assigned to each sample according to the unique barcode and were assembled by using FLASH [25]. The splicing sequences were filtered by QIIME (http: / / qiime.org accessed on 10 November 2021) to obtain high-quality clean tags then using the UCHIME algorithm (http: / / www.drive5.com/usearch/manual/uchime_algo.html, accessed on 10 November 2021) to detect and remove chimera sequences to obtain the effective tags. The effective tags were assigned to the same operational taxonomic units (OTUs) using the UPARSE software (http:/ / drive5.com/ uparse accessed on, 10 November 2021) at the $97 \%$ similarity level. The taxonomic identity of OTUs was assigned to bacteria using the RDP classifier in Greengenes Database and to fungi using the Blast algorithm in the UNITE database.

\subsection{Statistical Analysis}

Statistical analysis was performed using the SPSS Version 25.0 for Windows (SPSS, Chicago, IL, USA). Significant differences in soil properties, relative abundances and alpha diversity among the treatments were identified by Kruskal-Wallis test $(p<0.05)$. OTUs were analyzed for alpha and beta diversity for bacteria and fungi. Non-metric multidimensional scaling (NMDS) analysis and analysis of similarities (ANOSIM) based on the Bray-Curtis distance was conducted to detect the difference between samples for composition of both fungal and bacterial communities. Redundancy analysis (RDA) was used to assay the relationships between microbial community and soil properties. The NMDS and RDA were performed using the "vegan" package in R [26]. LEfSe multilevel species difference discriminant analysis evaluates the groups that have a significant effect on sample differences, and LDA linear discriminant analysis screens for groups that have a significant effect on differences between groups (LDA score > 2) [27]. The PICRUSt2 was used for functional prediction of 16S rRNA gene data [28], and the KEGG (Kyoto Encyclopedia of Genes and Genomes) database was consulted to obtain abundance prediction tables for $\mathrm{KO}$ (KEGG Orthology) function and KEGG metabolic pathway (KEGG pathway) abundance table. Fungal functional classification was analyzed using FUNGuild [29], and in order not to over-interpret the fungal functional groups, we retain the comparison results with "probable" and "high probability" according to confidence ranking, and then statistically analyzed the relative abundance of different functional groups. 


\section{Results}

\subsection{Soil Physicochemical Properties}

The response of Eucalyptus soil factors (soil water content, carbon, nitrogen, and phosphorus content) to the throughfall reduction is shown in Figure 1 and Table 1. Compared with control (CK) treatment, throughfall reduction (TR) treatment reduced soil water content (from July 2020 to January 2021) at 0-20 cm and $20-40 \mathrm{~cm}$ soil depth by $3.25 \%$ and $4.34 \%$, respectively (Figure 1). TR treatment significantly reduced soil AP content, but had no significant effect on other soil physicochemical properties. Among them, TR treatment reduced AP content by $45.82 \%$ and $57.8 \%$ at $0-20$ and $20-40 \mathrm{~cm}$ soil depth, respectively (Table 1).

Table 1. Values of soil chemical properties in TR and CK plots in different soil depths.

\begin{tabular}{ccccc}
\hline \multirow{2}{*}{ Soil Parameter } & \multicolumn{2}{c}{$\mathbf{0 - 2 0} \mathbf{~ c m}$} & \multicolumn{2}{c}{$\mathbf{2 0 - 4 0 ~ c m ~}$} \\
\cline { 2 - 5 } & CK & TR & CK & TR \\
\hline $\mathrm{TN}(\mathrm{g} / \mathrm{kg})$ & $0.53 \pm 0.07$ & $0.56 \pm 0.03$ & $0.34 \pm 0.03$ & $0.30 \pm 0.01$ \\
$\mathrm{TP}(\mathrm{g} / \mathrm{kg})$ & $0.29 \pm 0.06$ & $0.24 \pm 0.03$ & $0.30 \pm 0.03$ & $0.26 \pm 0.03$ \\
$\mathrm{AHN}(\mathrm{mg} / \mathrm{kg})$ & $65.26 \pm 1.49$ & $68.64 \pm 2.02$ & $53.65 \pm 3.21$ & $43.99 \pm 2.00$ \\
$\mathrm{AP}(\mathrm{mg} / \mathrm{kg})$ & $17.57 \pm 0.61 \mathrm{a}$ & $9.52 \pm 0.48 \mathrm{~b}$ & $13.01 \pm 0.29 \mathrm{a}$ & $5.49 \pm 0.21 \mathrm{~b}$ \\
$\mathrm{C}: \mathrm{N} \mathrm{ratio}$ & $1.77 \pm 0.21$ & $1.76 \pm 0.06$ & $2.15 \pm 0.14$ & $2.31 \pm 0.07$ \\
$\mathrm{TOC}(\%)$ & $0.93 \pm 0.03$ & $0.98 \pm 0.05$ & $0.71 \pm 0.02$ & $0.60 \pm 0.01$ \\
$\mathrm{SOM}(\mathrm{g} / \mathrm{kg})$ & $17.72 \pm 0.48$ & $18.51 \pm 0.97$ & $13.43 \pm 0.46$ & $11.44 \pm 0.27$ \\
\hline
\end{tabular}

Notes: Mean \pm SE are shown. CK, control; TR, throughfall reduction. Different lowercase letters $(a, b)$ indicate significant difference between the CK treatment and TR treatment in the same soil depth $(p<0.05)$, the same below. $\mathrm{TN}=$ total nitrogen, $\mathrm{TP}=$ total phosphorus, $\mathrm{AHN}=$ alkali-hydrolyzed nitrogen, $\mathrm{AP}=$ available phosphorus, $\mathrm{C}: \mathrm{N}$ ratio $=$ ratio of total organic carbon and nitrogen, $\mathrm{TOC}=$ total organic nitrogen, $\mathrm{SOM}=$ soil organic matter.

\subsection{OTU Cluster and Diversity Analysis}

A total of 45,329 to 71,211 (average: 56,647) and 53,170 to 74,021 (average: 62,894 ) valid sequences were consequently obtained for bacteria and fungi, respectively. These sequences were grouped into 5607 and 596 OTUs at the $97 \%$ similarity level for bacterial and fungi, respectively.

In the OTU level, CKA specific bacteria accounted for 33.94\% (874), TRA specific bacteria accounted for 31.88\% (821), CKB specific bacteria accounted for $29.39 \%$ (891), and TRB specific bacteria accounted for $39.18 \%$ (1188). CKA specific fungi accounted for $31.10 \%$ (93), TRA specific fungi accounted for $48.49 \%$ (145), CKB specific fungi accounted for $28.28 \%$ (84), and TRB specific fungi accounted for $48.15 \%$ (143) (Figure S2). It can be seen that the throughfall reduction changes the species composition of soil bacteria and fungi at the OTU level, and the species of soil fungal OTU change more.

To characterize the microbial community shifts more deeply, we dissected the observed bacterial and fungal community shifts by arranging OTUs according to their taxonomy and displaying their depletion or enrichment in the presence of TRA or TRB with respect to control (Figure S3). The results revealed that a total of 50 bacterial OTUs depleted significantly in the TRA treatment, whereas 37 bacterial OTUs enriched significantly in the TRA treatment (Figure S3a). A total of 69 bacterial OTUs depleted significantly in the TRA treatment, whereas 40 bacterial OTUs enriched significantly in the TRB treatment (Figure S3b). Bacterial depletion or enrichment of OTUs in the presence of TRA or TRB relative to controls mainly belonged to phylum Acidobacteria, Actinobacteria, and Proteobacteria. Strikingly, there was only one fungal out enriched significantly in the TRA treatment, which belonged to phylum Ascomycota (Figure S3c,d).

\subsection{Difference Analysis of Bacterial and Fungal Community Structure}

In the 0-20 cm soil depth, there were almost no bacteria species that played a significant role in the difference of bacterial community structure in the CK treatment, Phenylobacterium, Telmatospirillum, Burkholderia, Massilia, and Oxalobacteraceae played a significant role in 
the TR treatment. In the $20-40 \mathrm{~cm}$ soil depth, TK17, Rhodospirillaceae, Nitrosovibrio, and Nitrosomonadaceae played a significant role in the difference of bacterial community structure in the CK treatment, only Unspecified_Alphaproteobacteria played a significant role in the TR treatment (Figure 2a). Unlike the bacterial community, the species that played a significant role in the fungal community were very rare, and only existed in the in the TR treatment soil of 20-40 cm soil depth (Figure $2 \mathrm{~b}$ ).

(a)

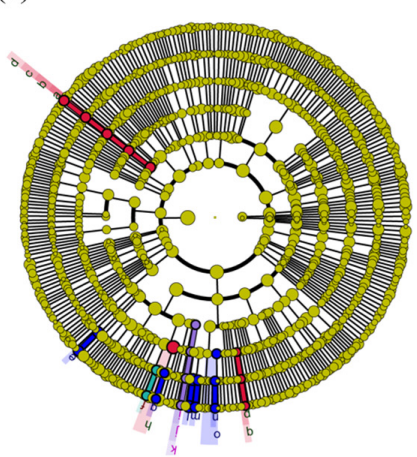

(b)

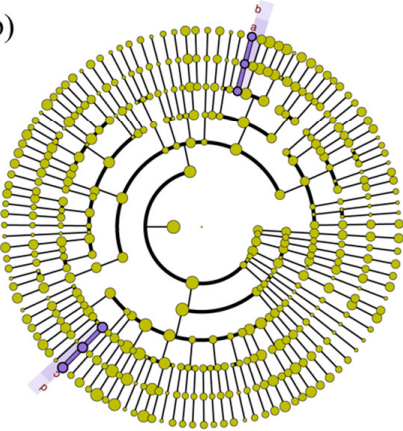

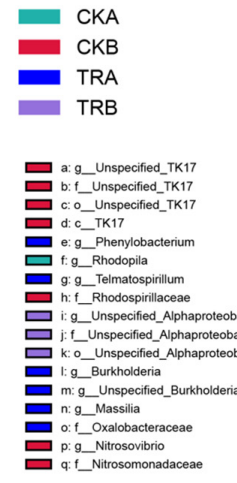

TRB
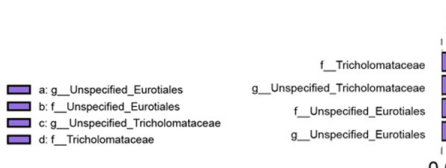
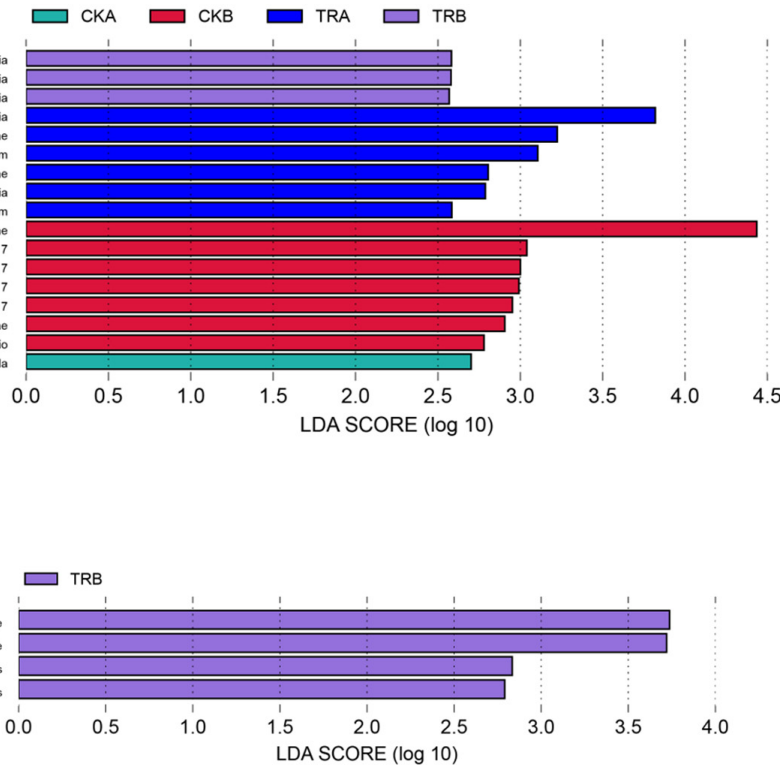

Figure 2. Linear discriminant analysis (LDA) of soil bacterial (a) and fungal communities (b).

\subsection{Diversity and Composition of Bacterial and Fungal Communities}

In the bacterial community, when compared to CK treatment, TR treatment had no significant effects on the alpha diversity-including Chao1, ACE, Shannon, Simpson, and Pielou $(p>0.05)$ (Table 2). The dominant bacterial phyla (mean relative abundance $>5 \%$ ) across all of the samples were Proteobacteria, Actinobacteria, Acidobacteria, and Chloroflexi, with relative abundances ranging from $33.62 \%$ to $41.28 \%, 18.79 \%$ to $21.82 \%, 15.84 \%$ to $21.73 \%$, and $3.82 \%$ to $9.09 \%$, respectively (Figure 3a). In addition, the phyla of $A D 3$, Planctomycetes, WPS_2, Verrucomicrobia, GAL15, and Firmicutes were less abundant (mean relative abundance $>1 \%$ but $<5 \%$ ), but were still detected across all samples. At the phylum level, TR treatment significantly increased the relative abundance of Acidobacteria in 0-20 cm soil depth, while other main phyla did not show significant change with any treatment used. Further taxonomical classification at the order level revealed that 17 order (with mean relative abundance $>1 \%$ ) were detected in all soil samples. Among them, the order Rhizobiales, Actinomycetales, Rhodospirillales, Acidobacteriales, Xanthomonadales, Solibacterales, Ellin6513, Gemmatales, Acidimicrobiales, and Solirubrobacterales were abundant (mean relative abundance $>2 \%$ ) in all treatments (Table S1). TR treatment significantly increased the relative abundance of Burkholderiales and Acidobacteriales in 0-20 cm soil depth but decreased the relative abundance of Rhodospirillales and Acidimicrobiales in $20-40 \mathrm{~cm}$ soil depth. In addition, TR treatment had no significant effect on other phyla (Table S1). 
Table 2. Diversity indices of fungal and bacterial community in Eucalyptus plantations.

\begin{tabular}{|c|c|c|c|c|c|c|c|}
\hline & Soil Depth & Treatments & Chao1 & ACE & Shannon & Simpson & Pielou \\
\hline \multirow{4}{*}{ Bacterial } & \multirow{2}{*}{$0-20 \mathrm{~cm}$} & CK & $876.876 \pm 78.848$ & $876.851 \pm 78.709$ & $6.318 \pm 0.090$ & $0.997 \pm 0.000$ & $0.933 \pm 0.001$ \\
\hline & & TR & $849.704 \pm 55.311$ & $849.279 \pm 54.769$ & $6.276 \pm 0.059$ & $0.997 \pm 0.000$ & $0.931 \pm 0.003$ \\
\hline & \multirow{2}{*}{$20-40 \mathrm{~cm}$} & CK & $875.495 \pm 29.869$ & $875.690 \pm 29.843$ & $6.284 \pm 0.053$ & $0.997 \pm 0.000$ & $0.928 \pm 0.003$ \\
\hline & & TR & $1017.267 \pm 217.043$ & $1017.153 \pm 216.812$ & $6.219 \pm 0.360$ & $0.995 \pm 0.003$ & $0.904 \pm 0.023$ \\
\hline \multirow{4}{*}{ Fungi } & \multirow{2}{*}{$0-20 \mathrm{~cm}$} & CK & $67.000 \pm 16.523$ & $66.848 \pm 16.440$ & $2.395 \pm 0.276$ & $0.811 \pm 0.046$ & $0.579 \pm 0.037 \mathrm{a}$ \\
\hline & & TR & $104.489 \pm 18.071$ & $103.401 \pm 18.060$ & $1.886 \pm 0.322$ & $0.709 \pm 0.081$ & $0.418 \pm 0.060 \mathrm{~b}$ \\
\hline & \multirow[b]{2}{*}{$20-40 \mathrm{~cm}$} & CK & $70.292 \pm 10.286$ & $70.668 \pm 10.314$ & $2.407 \pm 0.373$ & $0.807 \pm 0.052$ & $0.565 \pm 0.069$ \\
\hline & & TR & $112.432 \pm 30.579$ & $107.190 \pm 27.193$ & $2.111 \pm 0.340$ & $0.758 \pm 0.054$ & $0.466 \pm 0.056$ \\
\hline
\end{tabular}

Notes: Mean \pm SE are shown. Different lowercase letters in the same soil depth represent significant difference between the CK and TR treatment $(p<0.05)$.
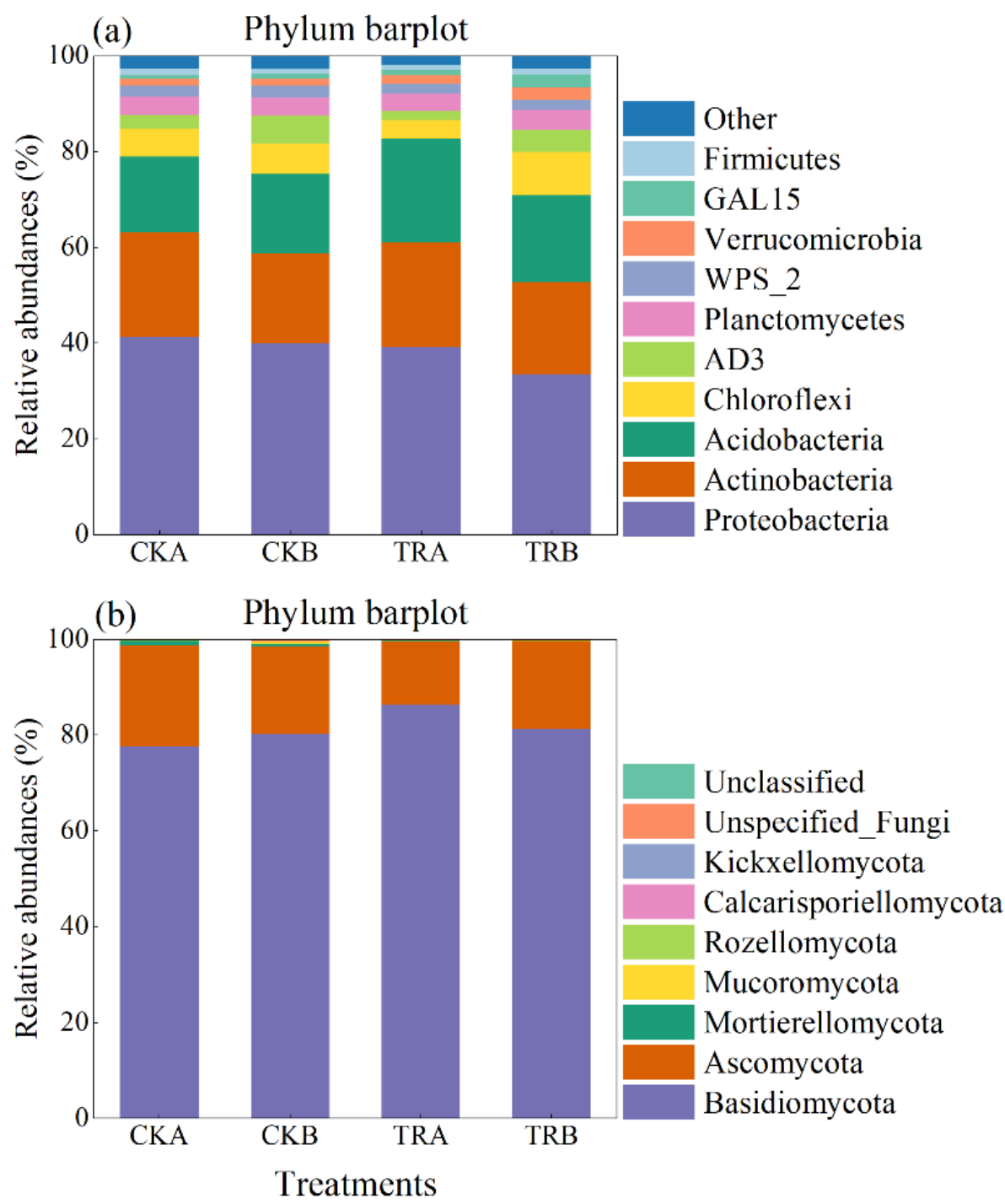

Figure 3. Relative abundance of the dominant bacterial (a) and fungal (b) groups at the phylum level under different treatments.

The dominant fungal phyla (mean relative abundance $>5 \%$ ) across all of the samples were Basidiomycota and Ascomycota, with relative abundances ranging from $80.15 \%$ to $86.38 \%$ and $13.19 \%$ to $21.17 \%$, respectively (Figure $3 \mathrm{~b}$ ). At the phylum level, the TR treatment had no significant effect on the abundance of bacteria and fungi. At the order level, TR significantly decreased the relative abundance of Hypocreales in $0-20 \mathrm{~cm}$ soil depth. On the contrary, compared with CK treatment, TR treatment increased the relative abundance of 
Hypocreales by $116 \%$ in $20-40 \mathrm{~cm}$ soil depth, but it did not reach a significant level $(p>0.05)$ (Table S1).

Non-metric multidimensional scaling (NMDS) based on the Bray-Curtis distance showed that TR treatment had a significant effect on the bacterial community $(p<0.05)$, but TR treatment had no significant effect on the fungal community (Figure 4). By RDA analysis, it was found that - at the community level—bacterial communities were significantly correlated with SWC, and fungal communities were significantly correlated with AP (Figure 5, Tables S2 and S3). To identify environmental drivers in our data set, we correlated distance-corrected dissimilarities of taxonomic community composition with those of environmental factors. Overall, SWC was the strongest correlate of taxonomic composition (ITS OTUs) (Figure S4).

\subsection{Response of Functional Groups of Bacterial and Fungal to Throughfall Reduction}

Based on PICRUSt2, functional analysis of bacterial populations was performed to obtain functional prediction information of different samples of bacteria. The sequencing data were compared using the KEGG database, and all samples involved a total of six types of biometabolic pathways: metabolism, genetic information processing, environmental information processing, cellular processes, human diseases, and organismal systems (Figure 6). Among them, metabolism was the main function with the abundance of $74.51-76.02 \%$. The analysis of the predicted functions of bacterial communities revealed that the abundance of the six primary functional depths of predicted genes did not differ significantly among treatments.

Further analysis of the predicted genes in the secondary functional depth revealed a total of amino acid metabolism, carbohydrate metabolism, replication and repair, cell motility, cell growth and death, endocrine system, a total of 46 sub-functions were identified, including amino acid metabolism, carbohydrate metabolism, replication and repair, cell motility, cell growth and death, endocrine system, drug resistance, antimicrobial, and membrane transport (Figure 6).

(a)

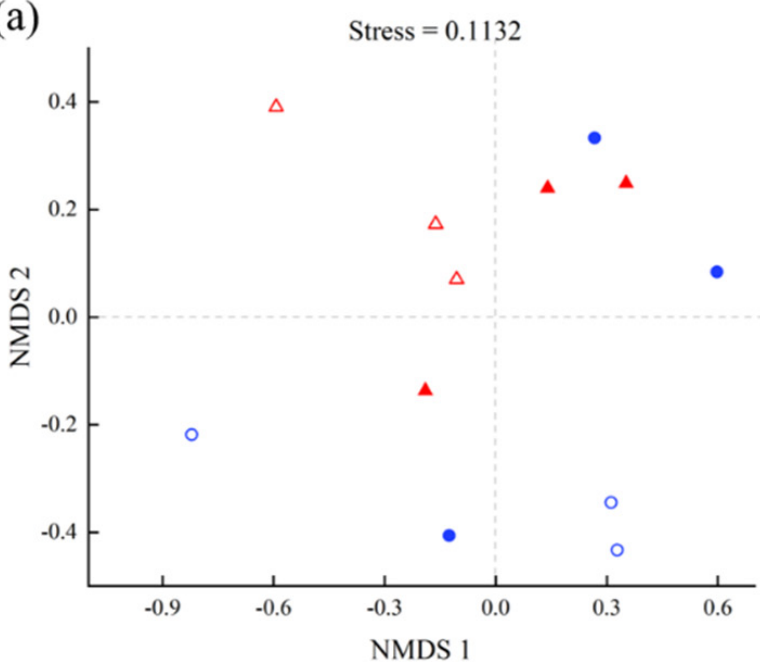

(b)

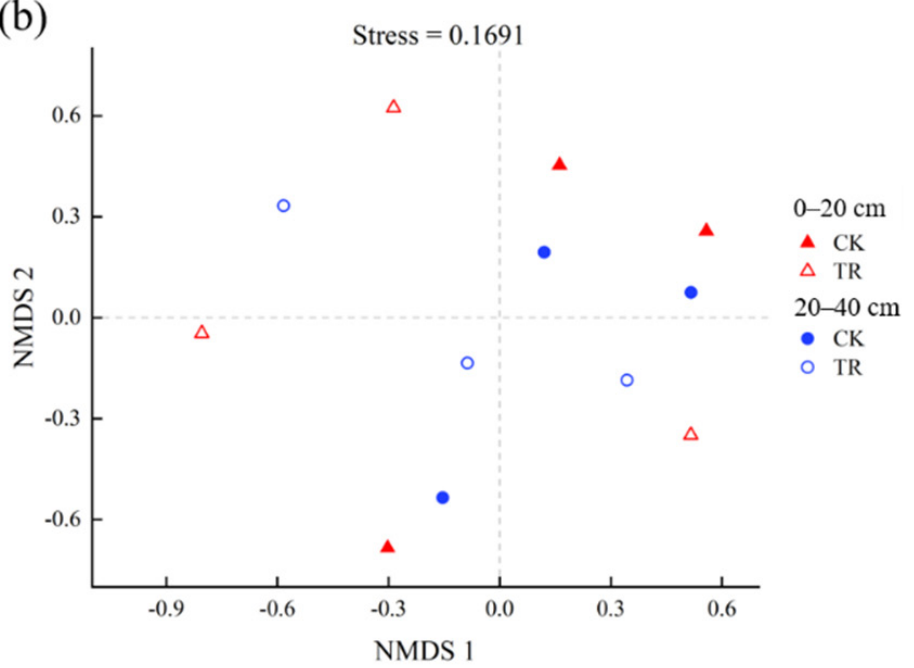

Figure 4. Non-metric multidimensional scaling (NMDS) analysis based on the Bray-Curtis distance for the bacterial (a) and fungal (b) community. The result of ANOSIM were listed. Triangle stand for 0-20 cm soil depth, circles stand for 20-40 cm soil depth. Open symbols stand for TR treatment, solid symbols stand for CK treatment. 
(a) RDA bacteria phyla Plot

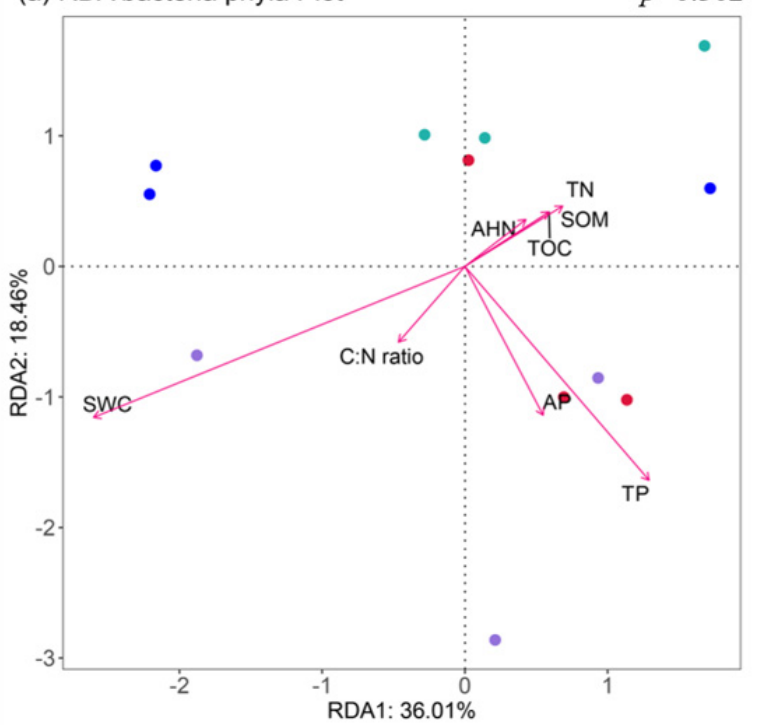

(b) RDA fungal phyla Plot

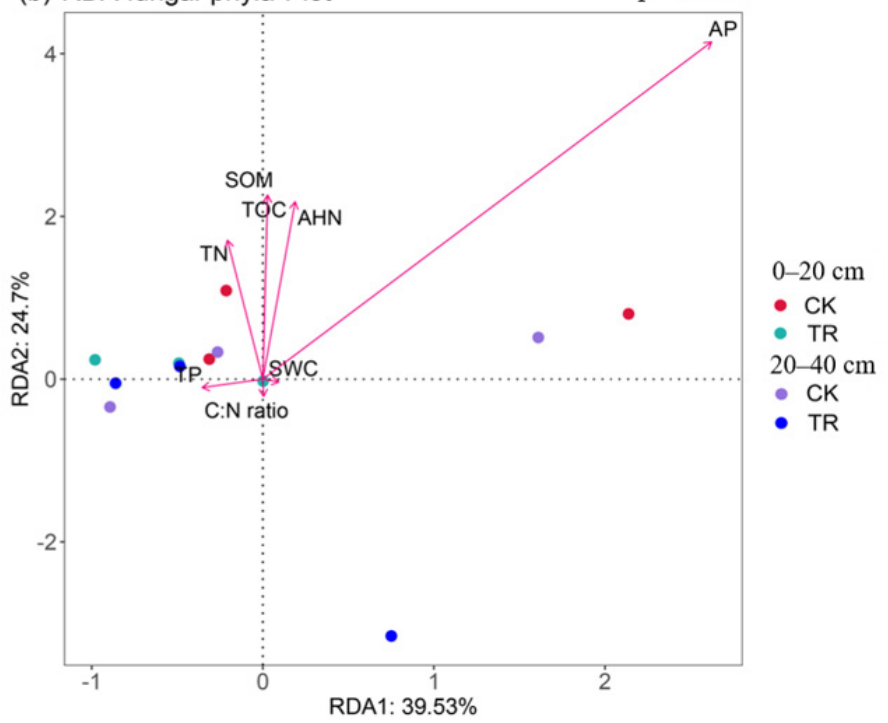

Figure 5. The biplot of redundancy analysis illustrated the relationships between bacterial (a) or fungal (b) community and the soil physicochemical properties. $\mathrm{TN}=$ total nitrogen, $\mathrm{TP}=$ total phosphorus, $\mathrm{AHN}=$ alkali-hydrolyzed nitrogen, $\mathrm{AP}=$ available phosphorus, $\mathrm{C}: \mathrm{N}$ ratio = ratio of total organic carbon and nitrogen, $\mathrm{SWC}=$ soil water content, $\mathrm{TOC}=$ total organic nitrogen, $\mathrm{SOM}=$ soil organic matter.

As can be seen from Figure S5, the abundance of secondary functional depth subfunctional genes changed between treatments, and signal transduction significantly decreased and xenobiotics biodegradation and metabolism significantly increased in the 0-20 cm soil depth after the throughfall reduction. However, there was no significant difference in the abundance of secondary functional depth sub-functional genes in the 20-40 cm soil depth.

The fungal communities of TR and CK treatment were compared using the FUNGuild database. In the $0-20 \mathrm{~cm}$ soil depth, the trophic mode of fungi in the CK group was dominated by Saprotroph (33.71\%), followed by Symbiotroph $(33.43 \%)$, Pathotroph and other types accounted for $7.95 \%$ and $24.91 \%$, respectively. After TR treatment, the trophic mode of fungi was dominated by Saprotroph (44.53\%), followed by Symbiotroph (28.29\%), and other types (22.51\%), with Pathotroph accounting for only $4.67 \%$; whereas TR treatment significantly increased the relative abundance of Saprotroph and decreased the relative abundance of Symbiotroph $(p<0.05)$ (Figure 7a). In the $20-40 \mathrm{~cm}$ soil depth, the trophic mode of fungi in the CK group was dominated by Saprotroph $(35.11 \%)$, followed by Symbiotroph (32.05\%), and Pathotroph and other types accounted for $4.2 \%$ and $28.64 \%$, respectively. After TR treatment, the trophic mode of fungi was dominated by Saprotroph $(37.74 \%)$, followed by Symbiotroph $(26.01 \%)$, and other types $(29.71 \%)$, while Pathotroph accounted for only $6.54 \%$, and TR treatment had no significant effect on the relative abundance of trophic mode of fungi (Figure $7 \mathrm{~b}$ ). 


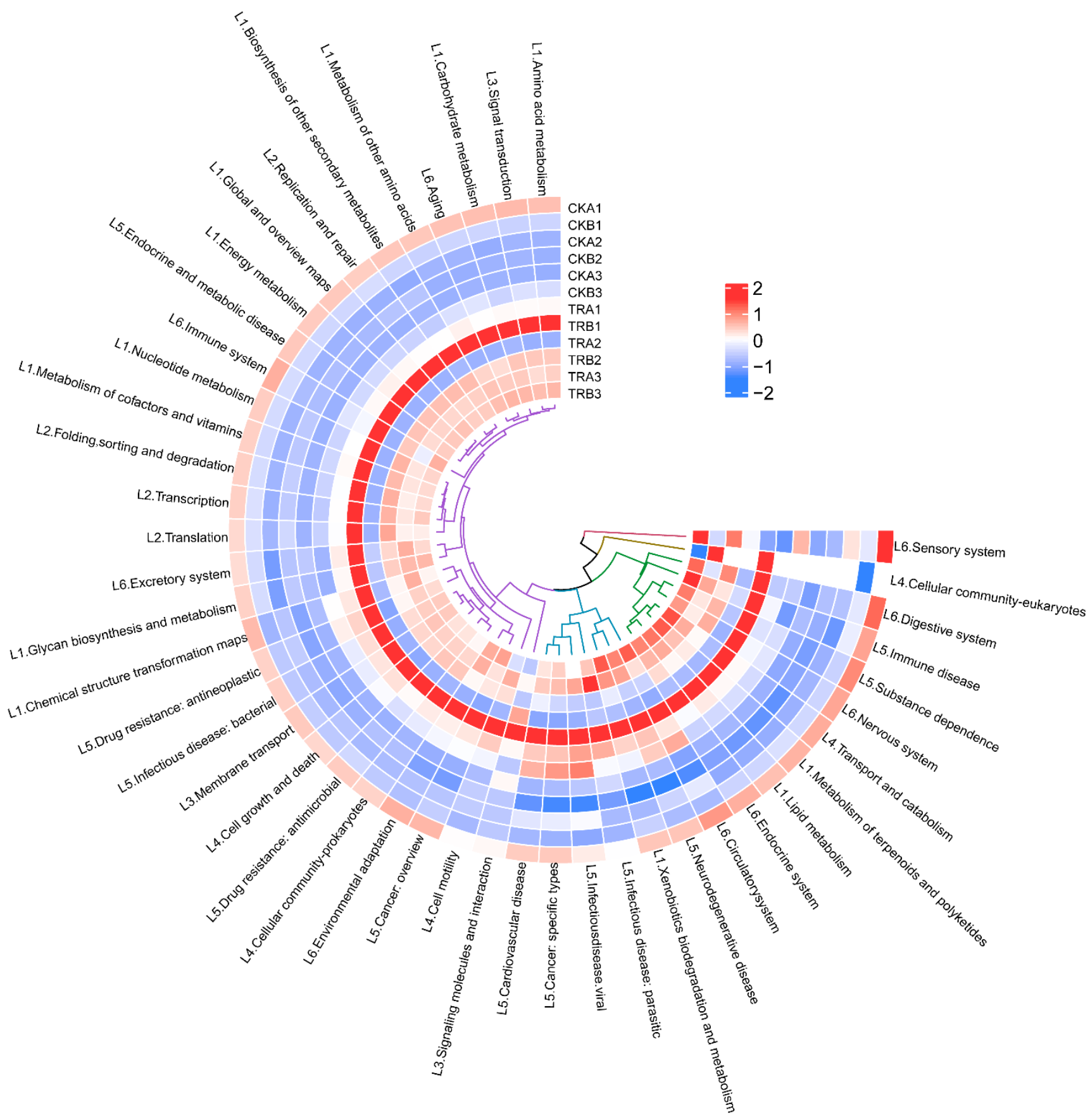

Figure 6. Heat map of PICRUSt2 based functional predicted for bacterial of different samples (hierarchy level 2). L1-L6 stands for hierarchy level 1: L1 stands for metabolism, L2 stands for genetic information processing, L3 stands for environmental information processing, L4 stands for cellular processes, L5 stands for human diseases, L6 stands for organismal systems. CKA1, CKA2, and CKA3 represent three repetitions of CKA, and so on. 

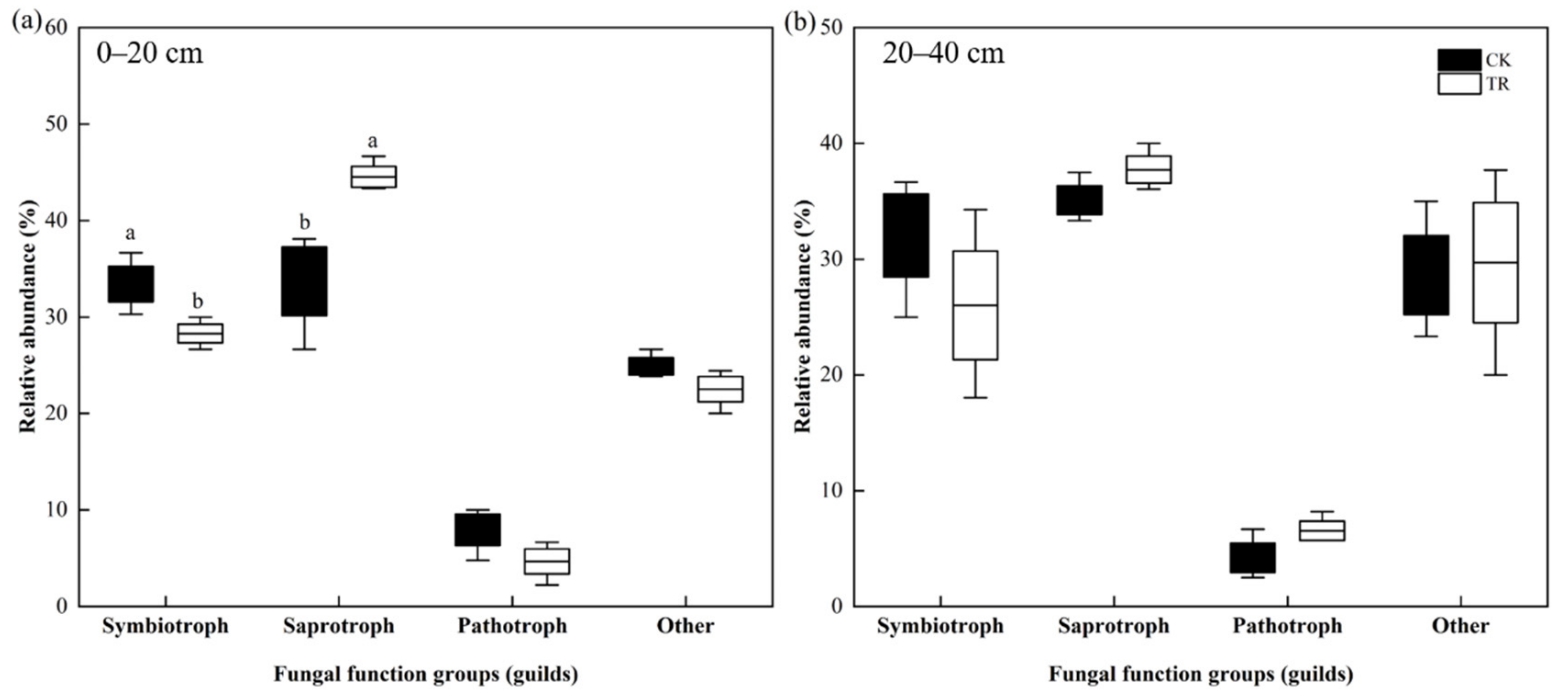

Figure 7. Effects of throughfall reduction on fungi trophic mode in 0-20 cm (a) and 20-40 cm (b) soil depth. Different lowercase letters represent significant differences between CK and TR treatment.

\section{Discussion}

\subsection{The Relationship among Throughfall Reduction, Soil Properties, and Microbial} Community Changes

Due to the strong monsoonal climate in the southern subtropical region, there are distinct wet and dry seasons. Of the total rainfall, $80 \%$ in the wet season. Compared with CK treatment, TR treatment reduced soil water content at $0-20 \mathrm{~cm}$ and $20-40 \mathrm{~cm}$ soil depth by $3.25 \%$ and $4.34 \%$, respectively from July 2020 to January 2021, the most important influence of throughfall reduction on soil properties should be SWC. Many studies have shown that the throughfall reduction can significantly reduce SWC $[19,30]$. The reason being that the SWC difference between treatments is not significant in our study may be that the intensity of throughfall reduction or the monitoring time of SWC is not enough.

Our study also found that TR treatment generally had no significant effect on the majority of soil properties, which is inconsistent with our third hypothesis. However, it could be seen that TR treatment can reduce soil AP content, which is similar to the results of Olatunji et al. [31]. Drought can reduce the mobility of phosphorus in soil, resulting in the lack of available phosphorus in soil under drought conditions. In addition, under the background of the change of precipitation pattern in the future, the throughfall reduction will lead to more phosphorus deficiency in the soil of southern China.

For soil microorganisms, a variety of biological and abiotic factors (such as vegetation [32], soil properties [33], and soil texture [34]) can affect their community structure. Soil C, N, and P are the main nutrient indexes of soil, in which $C$ is a necessary element for microbial growth. However, in our study, the TR treatment has no significant effect on the content of TOC, which is inconsistent with some studies $[35,36]$. The possible reason is that the soil of the test sample is poor, and the impact of the TR treatment on soil TOC is covered up. RDA analysis showed that soil factors explained $54.4 \%$ and $64.17 \%$ of the differences in bacterial and fungal community structure, respectively. Bacterial community composition was significantly correlated with SWC, which was consistent with the results of Cheng et al. [37], indicating that SWC is the dominant factor driving soil bacteria under drought conditions. Fungal community composition was significantly correlated with AP, which was consistent with the results of Wang et al. [38], TR treatment changed the soil physicochemical properties and affected the structure and composition of fungal community, but the relationship between soil physicochemical properties and fungal community structure is complex, and the mechanism of their influence by TR treatment needs to be further studied and determined. 


\subsection{Effects of Throughfall Reduction on Soil Bacterial Community Structure and Diversity}

Soil microorganisms are extremely sensitive to changes in environmental factors [39]. Different soil microbes have different abilities to use water and other resources in the soil, and therefore have different abilities to withstand water shortages. Proteobacteria and Acidobacteria are usually the most abundant in soil bacterial communities [40,41]. Although Actinomycota is predominant in soils, it is not distributed in all soils [40]. In this study, Proteobacteria, Actinobacteria, and Acidobacteria were the most abundant groups. Studies have shown that drought treatment can alter the composition of bacterial communities in arid areas, subtropical forests, and tropical rainforests [30,36,42]. Similarly, the throughfall reduction in this study also had a significant effect on bacterial community composition. This proves our first hypothesis that the throughfall reduction has a significant impact on the soil microbial community of Eucalyptus plantation. However, the $50 \%$ throughfall reduction did not affect the alpha diversity of soil bacterial community.

At the phylum and order levels, we found that the throughfall reduction had a significant effect on the relative abundance of some bacteria. The throughfall reduction significantly increased the relative abundance of Acidobacteria, Acidobacteriales, and Burkholderiales in 0-20 cm soil depth. It has been found that many soil factors-such as $\mathrm{pH}, \mathrm{TOC}, \mathrm{TN}, \mathrm{TP}$, nitrate nitrogen, ammonium nitrogen, soil humidity, soil temperature, and soil respirationall have an impact on the composition of Acidobacteria community structure [43]. Acidobacteria are generally considered to be more dominant in arid areas. Previous studies found that the relative abundance of Acidobacteria showed significant changes related to soil moisture. The ribosome synthesis rate decreased rapidly when soil moisture decreased, and increased rapidly when rewetting [44]. Acidobacteria are mostly acidophilic bacteria [45], Moreover, it has strong adaptability to the environment and plays an important role in the degradation of plant residues [46,47]. The soil in this study area is acidic, and Acidobacteria can degrade cellulose in low-oxygen and anoxic environments. Meanwhile, the throughfall reduction may increase the yield of total leaf litter that is difficult to decompose under Eucalyptus plantation, promote the expansion of soil Acidobacteria population, and thus increase the abundance of Acidobacteria population. Burkholderia is an aerobic bacterium. In the plantation, $50 \%$ of the forest is separated from the rain, which increases the aeration of the soil to a certain extent, and may increase the abundance of aerobic bacteria in this order, thus increasing the relative abundance of Burkholderia in the soil surface. In addition, the throughfall reduction significantly reduced the relative abundance of Acidimicrobiales and Rhodospirillales in the $20-40 \mathrm{~cm}$ soil. The sequence of Acidimicrobium, which is usually found in rocks, has been found in the soil of Eucalyptus plantations. It revealed the existence of a large number of new unknown groups of Actinomycetes in Acidimicrobiia [48]. It also indicated that the decrease of soil water content could reduce the abundance of Acidimicrobiales to a certain extent. Rhodospirillales mainly lives in water [49], it is a typical facultative trophic bacteria. The $50 \%$ throughfall reduction reduces the soil water content to a certain extent, which may indirectly reduce the abundance of red Rhodospirillales.

Prediction of bacterial community function in throughfall reduction using PICRUSt2, results showed that all samples involved six types of biometabolic pathways and $46 \mathrm{sub}-$ functions, showing rich functional diversity. TR treatment had no significant effect on gene abundance in the primary functional layer, and the major functional genes were all metabolism-related functions, indicating that metabolism plays an extremely important role in the soil of Eucalyptus plantations. In addition, signal transduction significantly decreased and xenobiotics biodegradation and metabolism significantly increased in the 0-20 cm soil depth after the throughfall reduction, the possible reason is that the sample bacteria treated by TR resist environmental stress by strengthening xenobiology biodegradation and metabolism.

\subsection{Effects of Throughfall Reduction on Soil Fungal Community Structure and Diversity}

At the community level, we found that the throughfall reduction did not significantly change the composition of soil fungal communities in Eucalyptus plantations, which may 
indicate that fungi are better adapted to drought than bacteria [50], and this also confirmed our second hypothesis. Studies have found that drought or water treatment have no significant effect on fungal communities in grassland ecosystems, because fungi are more drought-tolerant [44]. The main reason is that fungi can create a large network of mycelium to promote the remote transport of nutrients and water [51].

At the phylum level, the throughfall reduction decreased the relative abundance of Ascomycota in 0-20 cm soil depth and increased the relative abundance of Basidiomycota, but not significantly $(p>0.05)$. Thus, the relationship between the two types of fungi and the throughfall reduction showed an opposite response trend [19]. Ascomycetes and basidiomycetes were the most abundant groups in soil fungal community [52,53]. However, there are still few studies on the relationship between the two groups of fungi and the throughfall reduction [54], and the mechanism and possible reasons are still unclear. Our results are supported by a recent study that found that the arrival of rainy seasons in rainforests increases the abundance of Ascomycota in their soils [12]. Water or nutrient addition experiments confirmed that Ascomycota and Basidiomycota showed opposite response patterns to the changes of these environmental factors $[55,56]$. In the forests of northern China, the dominant genera in Ascomycota are directly proportional to soil water content, while the dominant genera in Basidiomycetes are inversely proportional to soil water content [57]. This shows that these two dominant groups compete for water and nutrients in soil.

For fungi, we classify them into three major functional groups according to the way they obtain nutrients: pathotroph, saprotroph, and symbiotroph. Among them, saprophytic and symbiotic fungi play very important roles in the nutrient cycling of soil. Specifically, saprophytic fungi are mainly involved in the decomposition of litter and organic matter formation; symbiotic fungi and plant roots are mutually beneficial and symbiotic, providing nutrients to plants, which can help plants to survive the poor living environment. The saprophytic fungi mainly obtain nutrients from plant or animal debris, while symbiotic fungi absorb nutrients from plants or soil. It has been shown that fertilization significantly increases the abundance of symbiotic fungi and decreases the abundance of saprophytic and pathogenic fungi [58]. In this study, TR treatment significantly reduced the abundance of symbiotic fungi and increased the abundance of saprophytic fungi at 0-20 cm soil depth. Studies have shown that the abundance of soil saprophytic fungi increased with decreasing precipitation [59]. In addition, saprophytic fungi may regulate soil hydraulic redistribution under low soil moisture conditions, which may also be responsible for the increase of saprophytic fungi communities. However, our results were inconsistent with the results of Zhao et al. [19], they concluded that drier dry season reduced the relative abundance of saprophytic fungi. It may be that drought reduced the yield and decomposition rate of litter in the plot [60].

\section{Conclusions}

Using amplicon sequencing technology, PICRUSt2 and FUNGuild platforms, we analyzed the composition, diversity, and function of soil fungal and bacterial communities. The results showed that bacterial and fungal communities responded differently to throughfall reduction (TR) treatment. A 50\% TR reduced soil water content and AP content, and then changed the composition and function of microbial community. TR treatment significantly altered the relative abundance of Acidobacteria and community structure, but did not affect the alpha diversity of the bacterial community and the relative abundance of fungal phylum and community composition. In addition, TR treatment had different effects on the function of bacterial and fungal communities. This study reports the response behaviors of soil microbial communities in the first years of the rainfall reduction experiment. To gain an even deeper understanding of the responsive behaviors and feedback pathways, it is suggested long-term reactions be studies in addition to short-term reactions. 
Supplementary Materials: The following are available online at https:/ / www.mdpi.com/article/ $10.3390 / \mathrm{f} 13010037 / \mathrm{s} 1$, Table S1: Changes in relative abundance $(\%)$ of the microorganisms at the phyla, class, and order level in the soil of Eucalyptus Plantations. Table S2: The result of envfit function of $\mathrm{R}$ packages indicated correlation of each soil property with overall bacterial communities for TR and CK. Table S3: The result of envfit function of $\mathrm{R}$ packages indicated correlation of each soil property with overall fungal communities for TR and CK. Figure S1: Photographs of the roof used to exclude the throughfall. Figure S2: Venn diagrams of OTUs distribution of bacterial (a) and fungal (b). Figure S3: Manhattan plots showing bacterial OTUs changed in TRA (a) or TRB (b) and fungal OTUs changed in TRA (c) or TRB (d) treatments with respect to control. Figure S4: Environmental drivers of soil microbial community composition. Figure S5: Significance test of bacterial function prediction (hierarchy level 2).

Author Contributions: J.L. and Q.Q. mainly contributed to the conceptualization of the work; Funding acquisition, Q.Q. and J.L.; Investigation, Y.L., J.K., and L.Y.; Methodology and analysis, Y.S., Q.H., and Y.L.; Project administration, Y.S., J.L., and Q.Q.; Resources, Y.L.; Software, Y.L.; Visualization, Q.Q. and Q.H.; Writing—original draft preparation, Y.L. and Q.Q.; Writing—review and editing, G.W. All authors have read and agreed to the published version of the manuscript.

Funding: This research was supported by the National Natural Science Foundation of China (Grant No. 31800527), National Key Research and Development Program of China (Grant No. 2016YFD0600201; Grant No. 2016YFD060020102), and China Scholarship Council Grant (Grant No. 202008440171).

Institutional Review Board Statement: Not applicable.

Informed Consent Statement: Not applicable.

Data Availability Statement: All data included in this study are available upon request by contact with the corresponding author.

Conflicts of Interest: The authors declare no conflict of interest.

\section{References}

1. Sun, S.; Zhao, H.; Xing, F.; Bai, Z.; Gao, Y.; Dong, Y.; Zhou, J.; Wu, Y.; Yang, Y. Response of soil microbial community structure to increased precipitation and nitrogen addition in a semiarid meadow steppe. Eur. J. Soil Sci. 2017, 68, 524-536. [CrossRef]

2. IP, CC. Climate change 2013: The physical science basis. In Proceedings of the , Working Group I Contribution to the IPCC Fifth Assessment Report, Stockholm, Sweden,, 30 September 2013.

3. Xu, Y.; Huang, X.; Zhang, Y.; Lin, W.; Lin, E. Statistical analyses of climate change scenarios over China in the 21st century. Adv. Clim. Chang. Res. 2005, 1, 80-83. (In Chinese)

4. Gao, J.Q.; Duan, M.Y.; Zhang, X.Y.; Li, Q.W.; Yu, F.H. Effects of frequency and intensity of drying-rewetting cycles on Hydrocotyle vulgaris growth and greenhouse gas emissions from wetland microcosms. Catena 2018, 164, 44-49. [CrossRef]

5. $\quad$ Engelhardt, I.C.; Niklaus, P.A.; Bizouard, F.; Breuil, M.C.; Barnard, R.L. Precipitation patterns and N availability alter plant-soil microbial C and N dynamics. Plant Soil 2021, 466, 151-163. [CrossRef]

6. $\quad$ Beier, C.; Beierkuhnlein, C.; Wohlgemuth, T.; Penuelas, J.; Emmett, B.; Korner, C.; Boeck, H.; Christensen, J.H.; Leuzinger, S.; Janssens, I.A.; et al. Precipitation manipulation experiments-challenges and recommendations for the future. Ecol. Lett. 2012, 15, 899-911. [CrossRef]

7. Carney, K.M.; Matson, P.A. Plant communities, soil microorganisms, and soil carbon cycling: Does altering the world belowground matter to ecosystem functioning? Ecosystems 2005, 8, 928-940. [CrossRef]

8. Gul, S.; Whalen, J.K.; Thomas, B.W.; Sachdeva, V.; Deng, H. Physico-chemical properties and microbial responses in biocharamended soils: Mechanisms and future directions. Agric. Ecosyst. Environ. 2015, 206, 46-59. [CrossRef]

9. Yao, Q.; Liu, J.; Yu, Z.; Li, Y.; Jin, J.; Liu, X.; Wang, G. Three years of biochar amendment alters soil physiochemical properties and fungal community composition in a black soil of northeast China. Soil Biol. Biochem. 2017, 110, 56-67. [CrossRef]

10. Drenovsky, R.E.; Vo, D.; Graham, K.J.; Scow, K.M. Soil water content and organic carbon availability are major determinants of soil microbial community composition. Microb. Ecol. 2004, 48, 424-430. [CrossRef]

11. Diaz-Pereira, E.; Marin Sanleandro, P.; Asencio, A.D. Effects of drought and water pulses on microbial functionality and the role of Cyanoprokaryota in the rhizospheres of gypsophytes. Sci. Total Environ. 2019, 691, 919-932. [CrossRef]

12. Brockett, B.F.T.; Prescott, C.E.; Grayston, S.J. Soil moisture is the major factor influencing microbial community structure and enzyme activities across seven biogeoclimatic zones in western Canada. Soil Biol. Biochem. 2012, 44, 9-20. [CrossRef]

13. Castro, H.F.; Classen, A.T.; Austin, E.E.; Norby, R.J.; Schadt, C.W. Soil microbial community responses to multiple experimental climate change drivers. Appl. Environ. Microbiol. 2010, 76, 999-1007. [CrossRef] [PubMed] 
14. Landesman, W.J.; Dighton, J. Response of soil microbial communities and the production of plant-available nitrogen to a two-year rainfall manipulation in the New Jersey Pinelands. Soil Biol. Biochem. 2010, 42, 1751-1758. [CrossRef]

15. Rodriguez-Caballero, E.; Belnap, J.; Büdel, B.; Crutzen, P.; Andreae, M.; Pöschl, U.; Weber, B. Dryland photoautotrophic soil surface communities endangered by global change. Nat. Geosc. 2018, 11, 185-189. [CrossRef]

16. Yu, S.; Mo, Q.; Li, Y.; Zou, B.; Xia, H.; Li, Z.; Wang, F. Changes in seasonal precipitation distribution but not annual amount affect litter decomposition in a secondary tropical forest. Ecol. Evol. 2019, 9, 11344-11352. [CrossRef]

17. Frossard, A.; Ramond, J.B.; Seely, M.; Cowan, D.A. Water regime history drives responses of soil Namib Desert microbial communities to wetting events. Sci. Rep. 2015, 5, 12263. [CrossRef] [PubMed]

18. Meisner, A.; Snoek, B.L.; Nesme, J.; Dent, E.; Jacquiod, S.; Classen, A.T.; Prieme, A. Soil microbial legacies differ following drying-rewetting and freezing-thawing cycles. ISME J. 2021, 15, 1207-1221. [CrossRef]

19. Zhao, Q.; Jian, S.; Nunan, N.; Maestre, F.T.; Tedersoo, L.; He, J.; Wei, H.; Tan, X.; Shen, W. Altered precipitation seasonality impacts the dominant fungal but rare bacterial taxa in subtropical forest soils. Biol. Fertil. Soils 2017, 53, 1-15. [CrossRef]

20. Arnold, R.J.; Xie, Y.J.; Luo, J.Z.; Wang, H.R.; Midgley, S.J. A tale of two genera: Exotic Eucalyptus and Acacia species in China. 1. domestication and research. Int. For. Rev. 2020, 22, 1-18. [CrossRef]

21. Yang, Y.J.; Liu, S.R.; Wang, H.; Chen, L.; Lu, L.H.; Cai, D.X. Reduction in throughfall reduces soil aggregate stability in two subtropical plantations. Eur. J. Soil. Sci. 2018, 70, 301-310. [CrossRef]

22. Fang, Y.T.; Gundersen, P.; Mo, J.M.; Zhu, W.X. Input and output of dissolved organic and inorganic nitrogen in subtropical forests of South China under high air pollution. Biogeosciences 2008, 5, 339-352. [CrossRef]

23. Wear, E.K.; Wilbanks, E.G.; Nelson, C.E.; Carlson, C.A. Primer selection impacts specific population abundances but not community dynamics in a monthly time-series $16 \mathrm{~S}$ rRNA gene amplicon analysis of coastal marine bacterioplankton. Environ. Microbiol. 2018, 20, 2709-2726. [CrossRef]

24. Lai, X.; Cao, L.; Tan, H.; Fang, S.; Huang, Y.; Zhou, S. Fungal communities from methane hydrate-bearing deep-sea marine sediments in South China Sea. ISME J. 2007, 1, 756-762. [CrossRef] [PubMed]

25. Lozupone, C.; Lladser, M.E.; Knights, D.; Stombaugh, J.; Knight, R. UniFrac: An effective distance metric for microbial community comparison. ISME J 2011, 5, 169-172. [CrossRef]

26. R Development Core Team. Development a Language and Environment for Statistical Computing; R Foundation for Statistical Computing: Vienna, Austria, 2015.

27. Segata, N.; Izard, J.; Waldron, L.; Gevers, D. Metagenomic biomarker discovery and explanation. Genome Biol. 2011, 12, R60. [CrossRef] [PubMed]

28. Douglas, G.M.; Maffei, V.J.; Zaneveld, J.R.; Yurgel, S.N.; Brown, J.R.; Taylor, C.M.; Huttenhower, C.; Langille, M.G.I. PICRUSt2 for prediction of metagenome functions. Nat. Biotechnol. 2020, 38, 1-5. [CrossRef] [PubMed]

29. Nguyen, N.H.; Song, Z.; Bates, S.T.; Branco, S.; Tedersoo, L.; Menke, J.; Schilling, J.S.; Kennedy, P.G. FUNGuild: An open annotation tool for parsing fungal community datasets by ecological guild. Fungal Ecol. 2016, 20, 241-248. [CrossRef]

30. Su, X.L.; Su, X.; Zhou, G.; Du, Z.; Deng, J. Drought accelerated recalcitrant carbon loss by changing soil aggregation and microbial communities in a subtropical forest. Soil Biol. Biochem. 2020, 148, 107898. [CrossRef]

31. Olatunji, O.A.; Luo, H.; Pan, K.; Tariq, A.; Sun, X.; Chen, W.; Wu, X.; Zhang, L.; Xiong, Q.; Li, Z. Influence of phosphorus application and water deficit on the soil microbiota of $\mathrm{N}_{2}$-fixing and non-N-fixing tree. Ecosphere 2018, 9, e02276. [CrossRef]

32. Nicole, W.; Yvette, P.; Ding, G.C. PhyloChip hybridization uncovered an enormous bacterial diversity in the rhizosphere of different potato cultivars: Many common and few cultivar-dependent taxa. FEMS Microbiol. Ecol. 2011, 75, 497-506.

33. Wu, T.H.; Dan, O.C.; Graham, J.H.; Martin, K.J.; Rosskopf, E.N. Comparison of soil bacterial communities under diverse agricultural land management and crop production practices. Microb. Ecol. 2008, 55, 293-310. [CrossRef] [PubMed]

34. Schutter, M.E.; Sandeno, J.M.; Dick, R.P. Seasonal, soil type, and alternative management influences on microbial communities of vegetable cropping systems. Biol. Fertil. Soils 2001, 34, 397-410.

35. Deng, L.; Peng, C.; Li, J.W.; Liu, Y.L.; Hai, X.Y.; Liu, Q.Y.; Huang, C.B.; Shangguan, Z.P.; Kuzyakov, Y. Drought effects on soil carbon and nitrogen dynamics in global natural ecosystems. Earth Sci. Rev. 2021, 214, 103501. [CrossRef]

36. Maestre, F.T.; Delgado-Baquerizo, M.; Jeffries, T.C.; Eldridge, D.J.; Ochoa, V.; Gozalo, B.; Quero, J.L.; Garcia-Gomez, M.; Gallardo, A.; Ulrich, W.; et al. Increasing aridity reduces soil microbial diversity and abundance in global drylands. Proc. Natl. Acad. Sci. USA 2015, 112, 15684-15689. [CrossRef] [PubMed]

37. Cheng, L.; Wang, X.; Guo, Q.Y. Relationship of soil bacterial community composition from different ecosystems on Qinghai-Tibet Plateau with environment factors. Agric. Res. Arid Areas 2019, 37, 18-26. (In Chinese)

38. Wang, N.N.; Yang, X.; Li, S.L.; Sui, X.; Han, S.J.; Feng, F.J. Effects of precipitation variation on the distribution pattern of soil fungal diversity in broadleaved Korean pine mixed forest. Chin. J. Appl. Ecol. 2013, 7, 1985-1990. (In Chinese)

39. Wardle, D.A.; Bardgett, R.D.; Klironomos, J.N.; Setala, H.; Van, W.H. Ecological linkages between aboveground and belowground biota. Science 2004, 304, 1629-1633. [CrossRef]

40. Janssen, P.H. Identifying the dominant soil bacterial taxa in libraries of 16S rRNA and 16S rRNA genes. Appl. Environ. Microbiol. 2006, 72, 1719-1728. [CrossRef]

41. McHugh, T.A.; Koch, G.W.; Schwartz, E. Minor changes in soil bacterial and fungal community composition occur in response to monsoon precipitation in a semiarid grassland. Microb. Ecol. 2014, 68, 370-378. [CrossRef] 
42. Bouskill, N.J.; Lim, H.C.; Borglin, S.; Salve, R.; Wood, T.E.; Silver, W.L.; Brodie, E.L. Pre-exposure to drought increases the resistance of tropical forest soil bacterial communities to extended drought. ISME J. 2013, 7, 384-394. [CrossRef]

43. Naether, A.; Foesel, B.U.; Naegele, V.; Wust, P.K.; Weinert, J.; Bonkowski, M.; Alt, F.; Oelmann, Y.; Polle, A.; Lohaus, G.; et al Environmental factors affect Acidobacterial communities below the subgroup level in grassland and forest soils. Appl. Environ. Microbiol. 2012, 78, 7398-7406. [CrossRef]

44. Barnard, R.L.; Osborne, C.A.; Firestone, M.K. Responses of soil bacterial and fungal communities to extreme desiccation and rewetting. ISME J. 2013, 7, 2229-2241. [CrossRef]

45. Barns, S.M.; Cain, E.C.; Sommerville, L.; Kuske, C.R. Acidobacteria phylum sequences in uranium-contaminated subsurface sediments greatly expand the known diversity within the phylum. Appl. Environ. Microbiol. 2007, 73, 3113-3116. [CrossRef]

46. Eichorst, S.A.; Kuske, C.R.; Schmidt, T.M. Influence of plant polymers on the distribution and cultivation of bacteria in the phylum Acidobacteria. Appl. Environ. Microbiol. 2011, 77, 586-596. [CrossRef] [PubMed]

47. Pankratov, T.A.; Ivanova, A.O.; Dedysh, S.N.; Liesack, W. Bacterial populations and environmental factors controlling cellulose degradation in an acidic Sphagnum peat. Environ. Microbiol. 2011, 13, 1800-1814. [CrossRef] [PubMed]

48. Zhang, J.; Xia, Z.; He, J.; Sun, H.; Zhang, L. Evaluation outcome of actinobacteria diversity in saline environment influenced by different DNA extraction methods. Acta Microbiol. Sin. 2013, 53, 746-757. (In Chinese)

49. Galachyants, A.D.; Krasnopeev, A.Y.; Podlesnaya, G.V.; Potapov, S.A.; Sukhanova, E.V.; Tikhonova, I.V.; Zimens, E.A.; Kabilov, M.R.; Zhuchenko, N.A.; Gorshkova, A.S.; et al. Diversity of aerobic anoxygenic phototrophs and rhodopsin-containing bacteria in the surface microlayer, water column and epilithic biofilms of Lake Baikal. Microorganisms 2021, 9, 842-863. [CrossRef] [PubMed]

50. Manzoni, S.; Schimel, J.P.; Porporato, A. Responses of soil microbial communities to water stress: Results from a meta-analysis. Ecology 2012, 93, 930-938. [CrossRef]

51. Joergensen, R.G.; Wichern, F. Quantitative assessment of the fungal contribution to microbial tissue in soil. Soil Biol. Biochem. 2008, 40, 2977-2991. [CrossRef]

52. Christiansen, C.T.; Haugwitz, M.S.; Prieme, A.; Nielsen, C.S.; Elberling, B.; Michelsen, A.; Grogan, P.; Blok, D. Enhanced summer warming reduces fungal decomposer diversity and litter mass loss more strongly in dry than in wet tundra. Glob. Chang. Biol. 2017, 23, 406-420. [CrossRef]

53. Rousk, J.; Baath, E.; Brookes, P.C.; Lauber, C.L.; Lozupone, C.; Caporaso, J.G.; Knight, R.; Fierer, N. Soil bacterial and fungal communities across a pH gradient in an arable soil. ISME J. 2010, 4, 1340-1351. [CrossRef]

54. Hawkes, C.V.; Kivlin, S.N.; Rocca, J.D.; Huguet, V.; Thomsen, M.A.; Suttle, K.B. Fungal community responses to precipitation Glob. Chang. Biol. 2015, 17, 1637-1645. [CrossRef]

55. Weber, C.F.; Rytas, V.; Kuske, C.R. Changes in fungal community composition in response to elevated atmospheric $\mathrm{CO}_{2}$ and nitrogen fertilization varies with soil horizon. Front. Microbiol. 2013, 4, 78-92. [CrossRef]

56. Chen, L.; Zhang, J.; Zhao, B.; Yan, P.; Zhou, G.; Xin, X. Effects of straw amendment and moisture on microbial communities in Chinese fluvo-aquic soil. J. Soils Sediments 2014, 14, 1829-1840. [CrossRef]

57. He, F.; Yang, B.; Wang, H.; Yan, Q.; Cao, Y.; He, X. Changes in composition and diversity of fungal communities along Quercus Mongolica forests developments in Northeast China. Appl. Soil Ecol. 2016, 100, 162-171. [CrossRef]

58. Chen, Z.J.; Gao, S.K.; Chen, Y.; He, P.H.; He, Q.; Qiu, Q.; Li, J.Y. Effects of short-term fertilization on soil fungal community structure and functional group in Eucalyptus artificial forest. Acta Ecol. Sin. 2020, 40, 3813-3821. (In Chinese)

59. Pena, R.; Polle, A. Attributing functions to ectomycorrhizal fungal identities in assemblages for nitrogen acquisition under stress. ISME J. 2013, 8, 321-330. [CrossRef] [PubMed]

60. Mcguire, K.L.; Zak, D.R.; Edwards, I.P.; Blackwood, C.B.; Upchurch, R. Slowed decomposition is biotically mediated in an ectomycorrhizal, tropical rain forest. Oecologia 2010, 164, 785-795. [CrossRef] [PubMed] 